\title{
Gerard de Nerval, Aurélia. Les Nuits d'octobre. Pandora. Promenades et souvenirs
}

\section{Pierangela Adinolfi}

\section{(2) OpenEdition}

1 Journals

\section{Edizione digitale}

URL: https://journals.openedition.org/studifrancesi/46122

DOI: 10.4000/studifrancesi.46122

ISSN: 2421-5856

\section{Editore}

Rosenberg \& Sellier

\section{Edizione cartacea}

Data di pubblicazione: 1 octobre 2007

Paginazione: 468-469

ISSN: 0039-2944

\section{Notizia bibliografica digitale}

Pierangela Adinolfi, «Gerard de Nerval, Aurélia. Les Nuits d'octobre. Pandora. Promenades et souvenirs», Studi Francesi [Online], 152 (LI | II) | 2007, online dal 30 novembre 2015, consultato il 24 novembre 2021. URL: http://journals.openedition.org/studifrancesi/46122 ; DOI: https://doi.org/10.4000/ studifrancesi.46122

Questo documento è stato generato automaticamente il 24 novembre 2021.

\section{(c) 9 (i) $\Theta$}

Studi Francesi è distribuita con Licenza Creative Commons Attribuzione - Non commerciale - Non opere derivate 4.0 Internazionale. 


\title{
Gerard de Nerval, Aurélia. Les Nuits d'octobre. Pandora. Promenades et souvenirs
}

\author{
Pierangela Adinolfi
}

\section{NOTIZIA}

GERARD DE NERVAL, Aurélia. Les Nuits d'octobre. Pandora. Promenades et souvenirs, préface de Gérard MACÉ, édition de Jean-Nicolas ILLouz, Paris, Gallimard, «Folio classique», 2005, pp. 299.

1 Il presente volume riunisce alcune delle principali opere nervaliane apparse tra il 1852 ed il 1855, periodo d'intensa e feconda produzione letteraria che corrisponde, sul piano biografico, al verificarsi delle più accentuate crisi nervose dell'autore. Mancano all'insieme della raccolta Les Chimères e Les Filles du Feu (1854), già pubblicate in un'edizione a parte. Preminente risulta, al contrario, il commento dedicato, nella «préface», ad Aurélia.

2 L'ultimo scritto di Nerval, uscito in parte postumo, è correttamente presentato come una sorta di testamento spirituale dell'autore, in cui si fondono tutti gli elementi della prosa e della lirica nervaliane: il racconto allucinato e quello ironico, malinconico, fantastico, autobiografico, l'ispirazione amorosa e la più urgente necessità dell'ascesi mistica. Aurélia non è solo la «descente aux enfers» in un mondo illusorio e parallelo a quello della cosiddetta razionalità, ma è anche il passo finale che Gérard compie verso la formazione di un universo personale, in cui poter collocare i tratti costitutivi della propria identità.

3 I temi del ricordo, dell'onirismo e della costruzione di un archetipo femminile che prende vita dalla commistione dei diversi profili di donna incontrati e descritti dall'autore sono presenti nei testi riuniti in questa edizione. Un'interessante appendice propone alcuni frammenti relativi a La Random, Aurélia e Promenades et souvenirs. Un 
puntuale apparato critico, una cronologia e un'aggiornata bibliografia arricchiscono il volume. Nel contesto degli scritti presi in esame, l'opera nervaliana si rivela, pertanto, attraverso la creazione di un'estetica del tutto originale, uno dei centri nevralgici della letteratura francese del xix secolo. 